\title{
Studying the Factors Affecting the Attitude and Intention of Buying Organic food consumers: structural equation model
}

Leila Andervazh

Dept. of Business management, Khorramshahr- Persian Gulf international Branch. Islamic Azad University, Khorramshahr, Iran.

Sahar Jalili

Dept. of Fisheries, Abadan Branch, Islamic Azad University, Abadan, Iran

Samaneh Zanjani

* Dept. of Health Education and Promotion, Science and Research Branch, Islamic Azad University, Tehran, Iran (Corresponding Author) Email: zanjani.samaneh@gmail.com

Received: 24 August 2019

Accepted: 09 January 2020

Doi: $10.29252 /$ ijhehp.8.1.35

\section{ABSTRACT}

Background and Objectives: The use of organic food products is a new way of thinking about food, health and nature. The attitude of consumers towards organic products and the factors affecting the consumption of these products is essential for further development and production, and the improvement of the quality of these products. In this regard, the present study was conducted to investigate the effective factors on the attitude and intention of purchasing organic food consumers. Materials and Methods: In this cross-sectional study, 384 people who were referred to 4 centers of organic products in Tehran were selected by systematic random sampling. The research data were collected based on a questionnaire based on constructs of attitude model towards organic products and consumers intentions and behavior purchase after determining the validity and reliability of questionnaire. Analysis and testing of research hypotheses were done using the SPSS version 22 and Amos version 23.

Results: According to the results of the present study, consumer perception of price $(\beta=0.67)$ and subjective norm $(\beta=0.43)$ have the most influence on consumers' attitude towards organic food. Also, availability, health awareness and knowledge of organic food respectively by quantity of $(\beta=0.26),(\beta=0.15),(\beta=0.14)$ affect the attitude of consumers towards organic food, also this attitude has a positive and significant effect on consumers' intent and behavior of purchase. R2 was calculated for the consumers' intent and behavior of purchase variables 0.42 and 0.53 and 0.89 for attitude.

Conclusion: Due to the direct effect of organic nutritional knowledge on consumers' attitude, intent and behavior, it is recommended that companies producing these products make extensive promotions in the field of awareness of the community about these products and their benefits.

Keywords: Organic products, health awareness, attitude Paper Type: Research Article.

Citation (Vancouver): Andervazh L, Jalili S, Zanjani S. Studying the Factors Affecting the Attitude and Intention of Buying Organic food consumers: structural equation model. Iran J Health Educ Health Promot. Spring 2020;8(1): 35-44. [Persian]

Citation (APA): Andervazh L., Jalili S., Zanjani S. (Spring 2020). Studying the Factors Affecting the Attitude and Intention of Buying Organic food consumers: structural equation model. Iranian Journal of Health Education \& Health Promotion., 8(1), 35-44. [Persian] 


\section{بررسى عوامل موثر بر نكرش و قصد خريد مصرفكنندكان مواد غذايى اركَانيك:

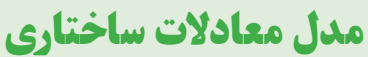

\section{0 -}

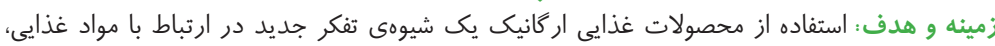

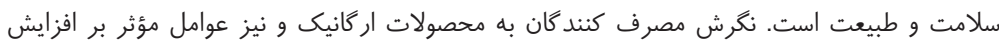

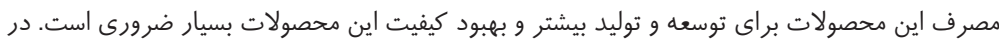

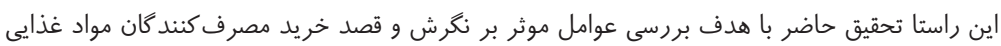

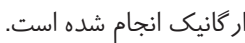

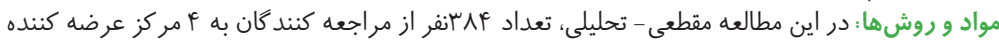

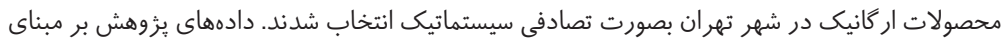

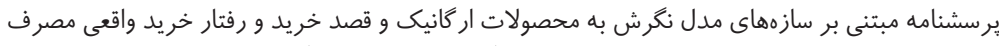

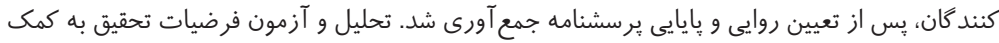

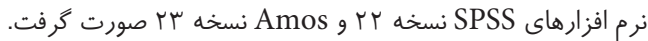

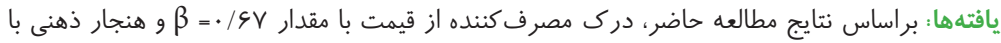

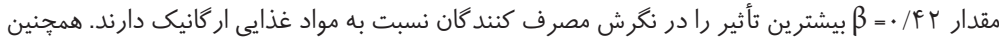

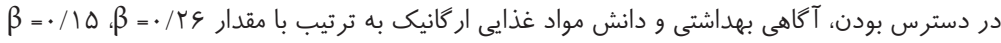

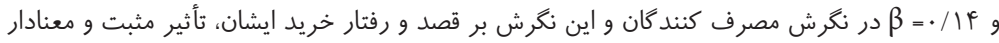

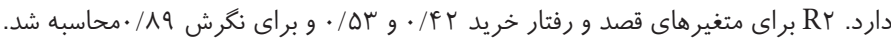

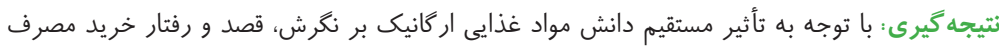

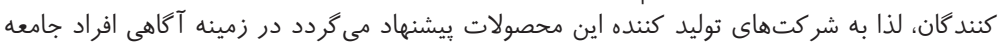

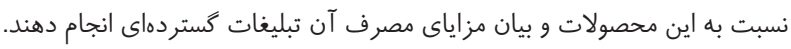

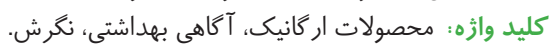

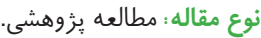

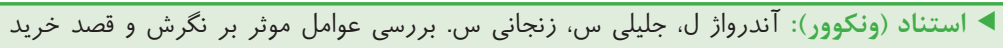

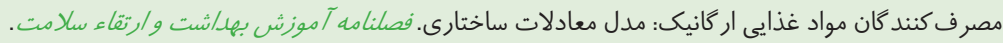

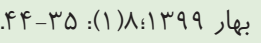

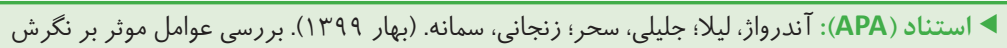

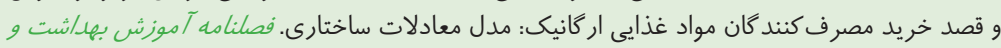

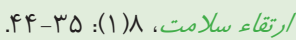

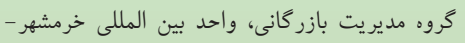

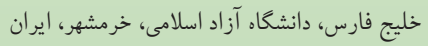
سحر جليلى كروه شيلات، واحد آبادان، دانشكاء آزاد اسلامى، آبادان،

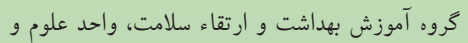
تحقيقات، دانشكاء آزاد اسلامى، تهران، ايران(نو يسندة مسئول): zanjani.samaneh@gmail.com

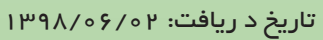

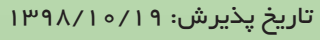


اركانيك به عنوان بخشى از روند بازاريابى در حال كَترش است

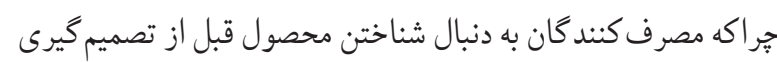

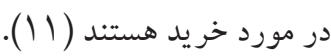
مصرف محصولات اركانيك به ترتيب اولويت، به سلامت،

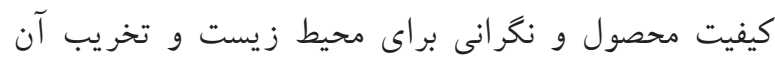

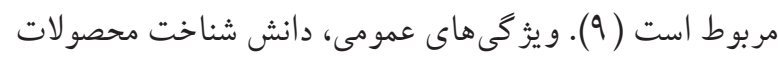

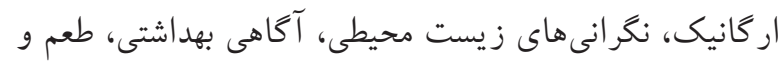

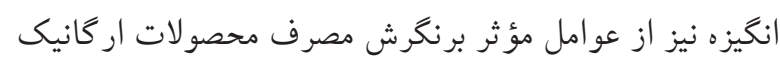

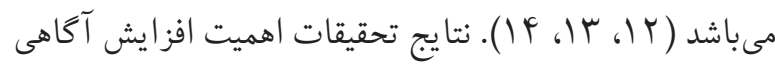

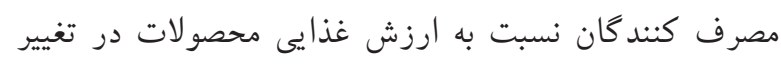

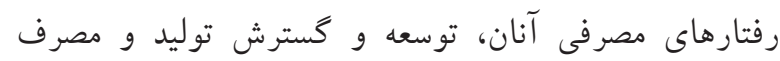

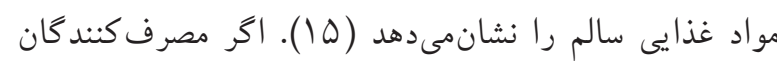

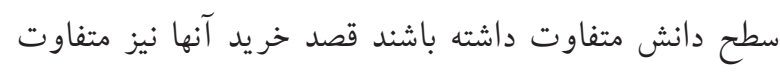
خواهد بود. خر يد محصول دوستدار محيط زيست نمى تواند از

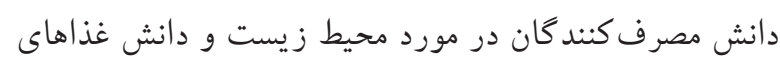

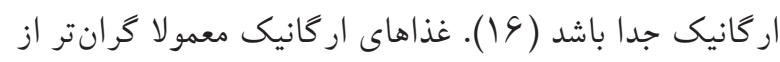

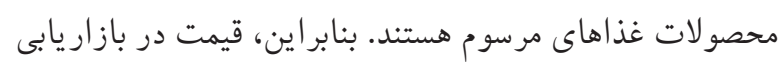

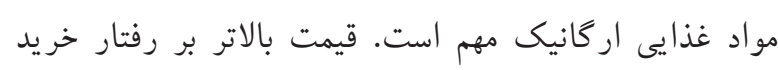

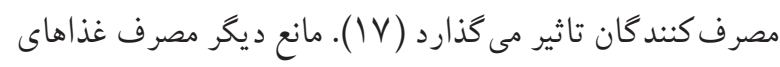

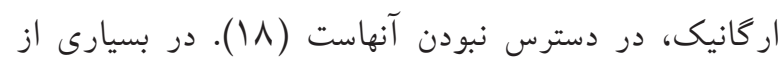

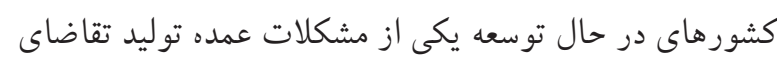

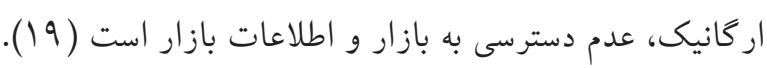

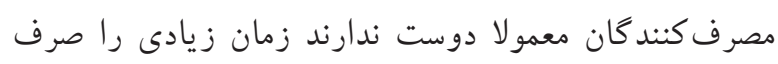

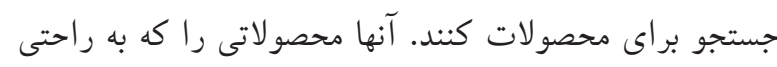

در دسترس هستند ترجيح مىدهند (Y. (Y).

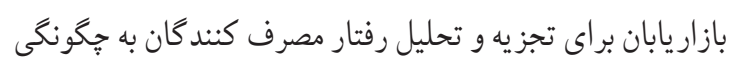

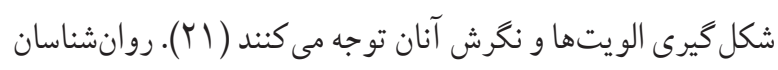

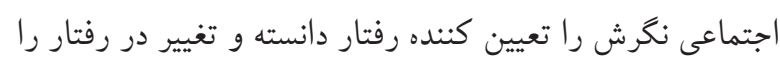

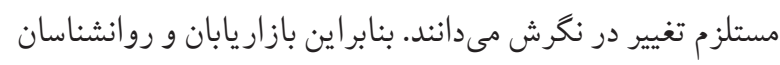

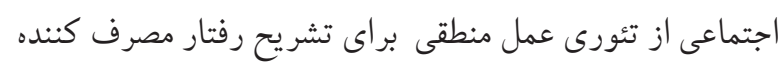

مصرف كندكان در طول دهه كذشته به دليل بحران غذايى ماندا

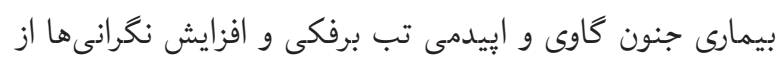

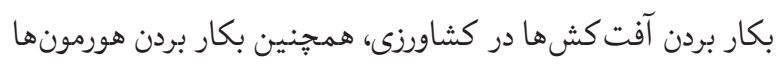

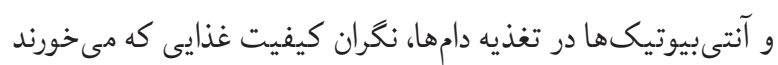

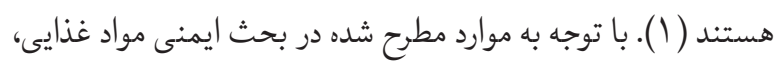

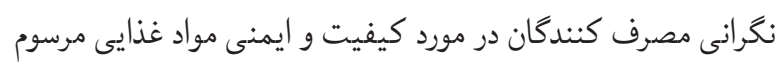

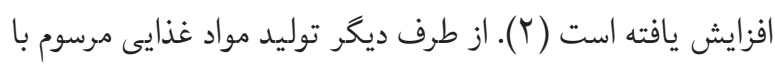

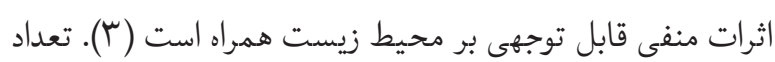
زيادى از مصرف كندكان از سراسر جهان با مشكلات زيست محيطى

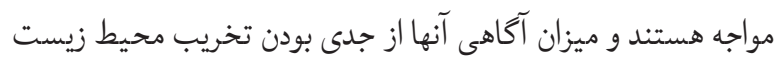
بيشتر شده است و شرايط بد زيست محيطى موجب تهديد سلامت أنات و تندرستى مصرف كندكان مىشود (广) ).

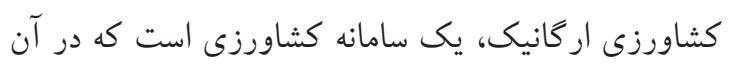

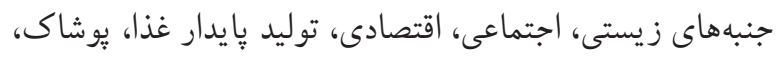

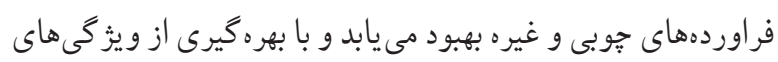
طبيعى گياهان، دام و محيط؛ كيفيت نظام كشاورزى و محيط زئيس

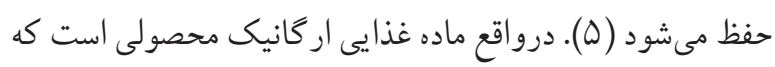

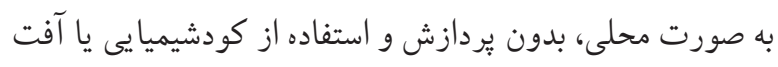
كشها رشد مى كند (9).

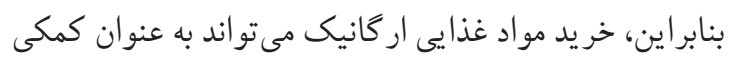

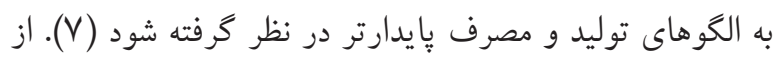

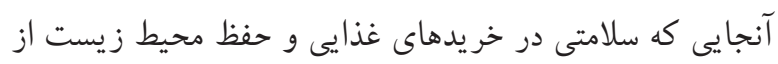

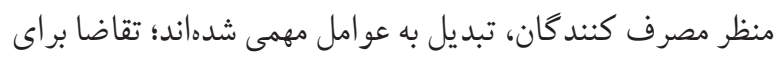

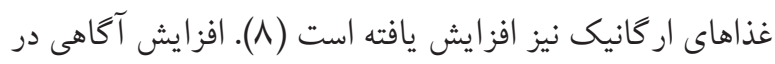

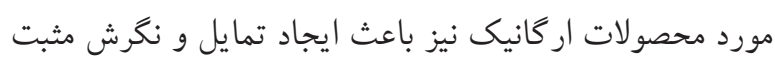

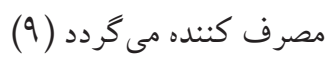
آكاهى زيست محيطى و افز ايش علاقه مصرف كند كان بن به اين

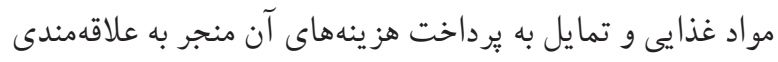

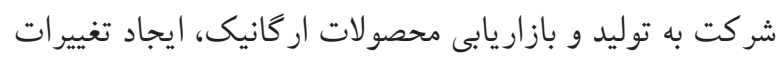

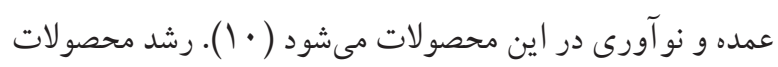


ابزار كرد آورى دادهها در اين بثزوهش برسشنامهاى شامل دو

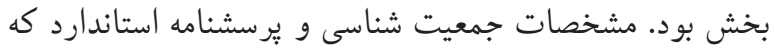

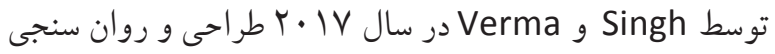

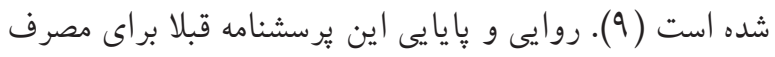

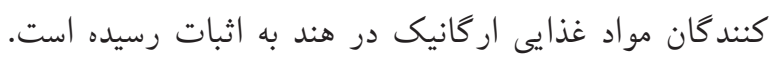

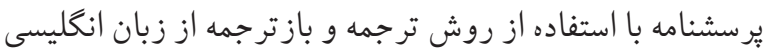
به فارسى تبديل شد. روايى صورى نسخه فارسى يرسشنامهها به صورت كيفى توسط گروه هدف و همجنين طبق نظر متخصصين ادبيات و زبان فارسى انجام گرفت. براى بررسى روايى كيفى محتوا

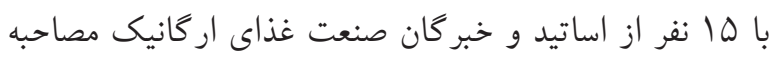

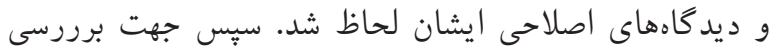

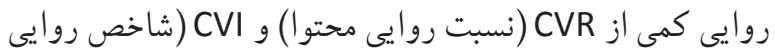

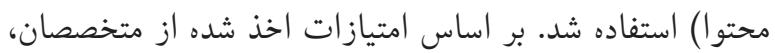
ميانگين نسبت روايى يرسشنامه •^/ •محاسبه شد. جهت تعيين

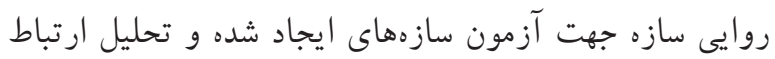

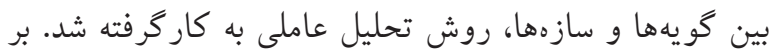
اساس نتايج حاصله، در اين تحليل شاخصهاى برازش در سطح

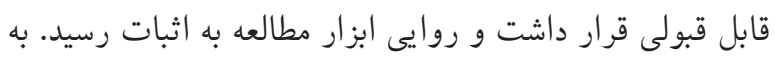

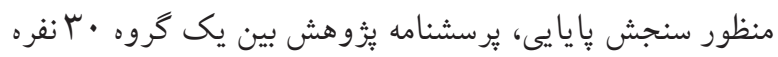

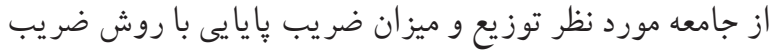

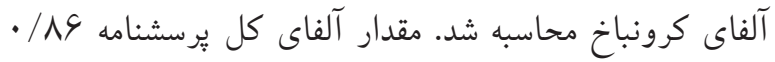

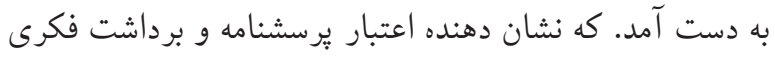
مناسب و يكسان پاسخگو يان از محتواى آن بود.

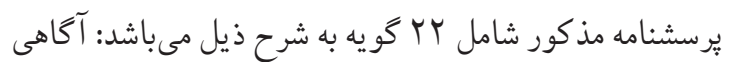

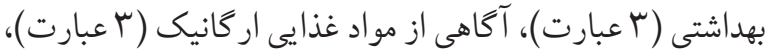

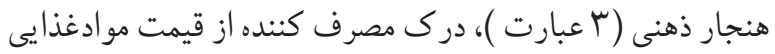

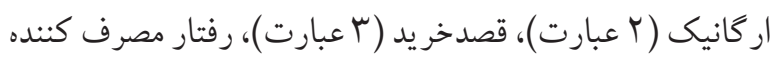

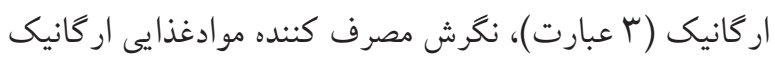

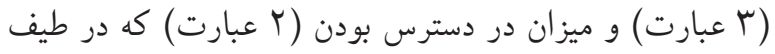
ليكرت ينج امتيازى، كاملا مخالف ( ا امتياز)، مخالف (Y امتياز)، نظرى ندارم (ץ امتياز)، موافق (ץ امتياز) و كاملا موافق (ه امتياز)
در انتخاب مواد غذايى اركانيك استفاده كردهاند (T ب، شY). تئورى عمل منطقى در واقع مدلى در ارتباط با عوامل رفتارى مىباشد كه با قصد آكاهانه صورت مى گيرد. اين مدل شامل جهار

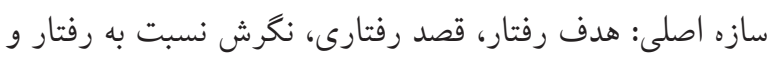
هنجارهاى ذهنى است. طبق اين تئورى، قصد رفتارى مهمتر ين عامل تعيين كننده رفتار است. تئورى عمل منطقى براى توضيح تقريبا هر كونه رفتار انسانى، از جمله رفتار خريد و رفتار مصرفى طراحى گرديده است (YY). با توجه به وسعت و جمعيت بالاى شهر تهران و مسائلى كه اين

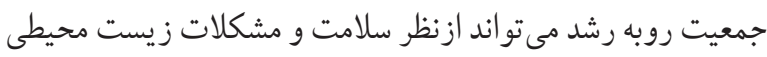

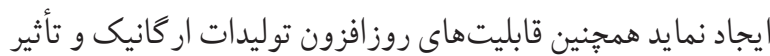
مثبت تقاضاى مصرف كنند

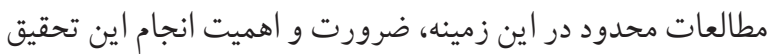

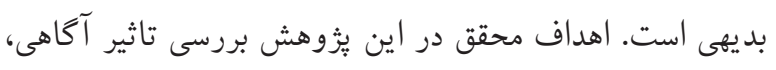
دانش، هنجارهاى ذهنى، قيمت درك شده و دسترسى مصرف كننده

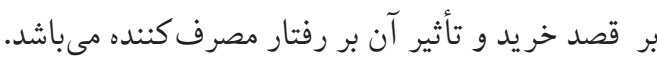

$$
\text { مو اد و روش ها }
$$

مطالعه حاضر از نوع تحقيق توصيفى- بيمايشى است. حجم نمونه

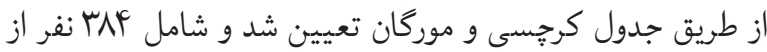
مصرف كنندگان مواد غذايى ارگانيك در شهر تهران بود كه بصورت تصادفى خوشهاى انتخاب شدند. بدين صورت كه از مجموع V فروشكاه

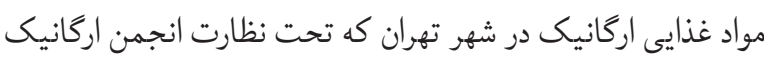
تهران قرار دارند و در مناطق جغرافيايى شرق، غرب، شمال و مركز

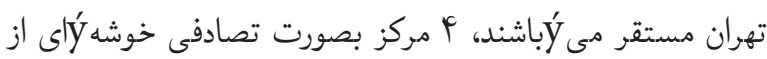
مناطق شمال و غرب تهران انتخاب و در ساعات مختلف شبانه روز

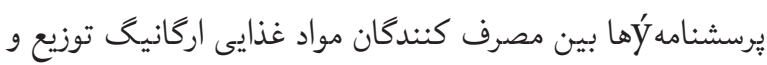

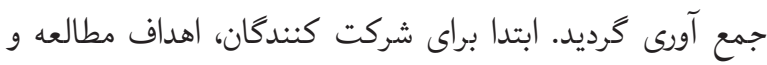
محرمانه بودن اطلاعات دريافتى توضيح داده شد و يس از دريافت بردي

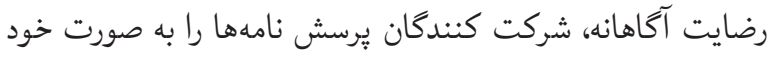

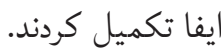


جدول ا. اطلاعات جمعيت شناختى افراد مورد مطالعه

\begin{tabular}{|c|c|c|c|}
\hline درصد & تعداد & وضعيت & متغير ها \\
\hline r & 91 & زن & \multirow[b]{2}{*}{ جنس } \\
\hline$V s / \mu$ & rq & مرد & \\
\hline $19 / 9$ & 90 & زير ·ץ سال & \multirow{4}{*}{ سن } \\
\hline$\leftarrow V / V$ & IAr & هץ--וس سال & \\
\hline$r \mid / s$ & $\Lambda \mu$ & 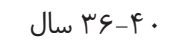 & \\
\hline$|F /|$ & $\Delta F$ & بالاى · r سال & \\
\hline $10 / 4$ & s. & ديڤلم و پإين تر & \multirow{5}{*}{ سطح تحصيلات } \\
\hline $1 \cdot / r$ & rq & فوق دييلم & \\
\hline r & 199 & ليسانس & \\
\hline$r N / r$ & 1.9 & فوق ليسانس & \\
\hline$r, \xi$ & 1 . & د دكترا & \\
\hline
\end{tabular}

تحصيلات / / / درصد شر كت كنند كان در مقطع ليسانس بود.

جزئيات مشخصات جمعيت شناختى در جدول شماره آ آورده شده است.
رتبه بندى مىشود.

براى تحليل دادهها در دو بخش توصيفى و استنباطى از شاخصهاى

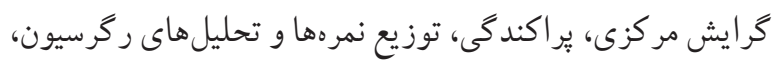

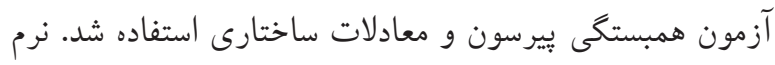

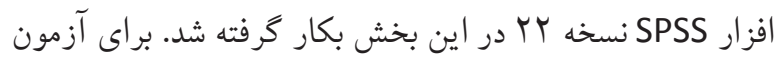

تحليلى از تحليل عاملى تاييدى و ضر يب مسير با استفاده از نرم

افزار Amos نسخه سب استفاده كرديد.

يافته هـا

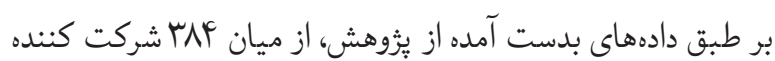

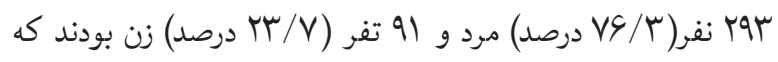
بيشترين آنها در گروه سنى هـ-اس سال قرار داشتند.

جدول r. شاخصهاى برازش مدل بيرونى

\begin{tabular}{|c|c|c|c|c|c|c|c|c|c|}
\hline در دسترس & ى دركن مصد از قيمت & هنجار ذهن & غذايى آكاهى از موانيك & بهداشتى & محصولات ار كانيك مصرف & رفتار مصرف & قصد خريد & حد مطلوب & شاخصهاى برازش بيرونى \\
\hline$\cdot / V^{c}$ & $\cdot / V^{\mu}$ &.$/ 199$ & $\cdot / 14$ & $\cdot / \lambda F$ & $\cdot / V G$ & $\cdot / \vee \wedge$ & . /Ar & $>\cdot / V$ & آلفاى كرونباخ \\
\hline$\cdot / \mathrm{V} \Delta$ & $\cdot / \mathrm{\Lambda}$ & $\cdot / 199$ & $\cdot / V V$ & $\cdot / 11$ & ./Vs & $\cdot / V Y$ & $\cdot / \wedge \varsigma$ & $>\cdot / V$ & ضريب يايايى \\
\hline .191 &.$/ 9 \Lambda$ &.$/ 9 V$ & .19. & س & ./VG & .194 & .14. & $>\cdot 10$ & ميانگين واريانس \\
\hline
\end{tabular}

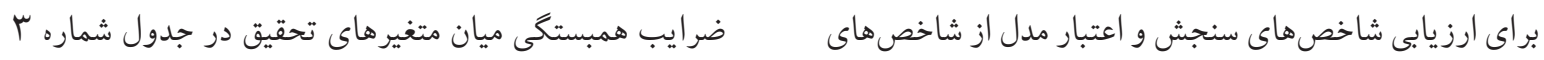

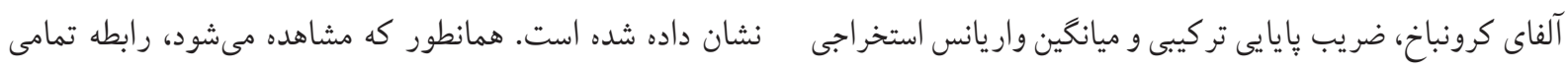

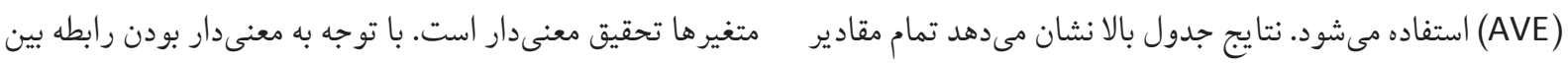

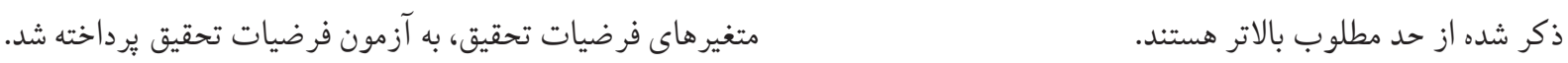

جدول سّ. ضريب همبستخى ميان متغير هاى تحقيق

\begin{tabular}{|c|c|c|c|c|c|c|c|c|}
\hline درد دسترس & كننده از قصيمت مصرف & هنجار ذهنى & آمَاهى اراد غذايى & بهداشتى & نكرش به مصرف & رنتار مصرف ' & قصد خريد & متغيرها \\
\hline & & & & & & & 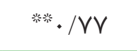 & قصد خريد \\
\hline & & & & & & 荬粪. $/ \vee q$ & 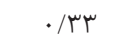 & رفتار مصرف كننده \\
\hline & & & & & * &.$/ O T$ & $\cdot / \mathcal{E V}$ & نكرش به مصرف محصولات ار گانيك \\
\hline & & & & 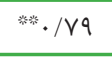 & 粆. $/ 9 V$ & .190 & ***.* & آكاهى بهداشتى \\
\hline & & & 檏. $/ \mathrm{VV}$ & 䅉. $/ 9 \Lambda$ & 檏. $/ 9 \mu$ & $\cdot / \Delta r$ & $\cdot / \mu 1$ & آكاهى از مواد غذايى اركانيك \\
\hline & & 䋓./Ar & $\cdot / 4$. & $\stackrel{* * 09}{*} \cdot / 09$ & * & ${ }^{*}, 10$. & $\cdot / 41$ & هنجار ذهنى \\
\hline & 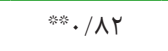 & .109 & $\cdot / \Delta Q T$ & .190 & 蝶. $/$ Fr & 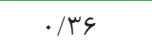 & $\cdot / 4$ & درك مصرف كننده از قيمت \\
\hline * & . $/$ k &.$/ \Delta T$ & .109 & .199 & * $\cdot / 9 \mu$ & $\cdot /$ er & $\cdot /$ r & در دسترس بودن \\
\hline
\end{tabular}




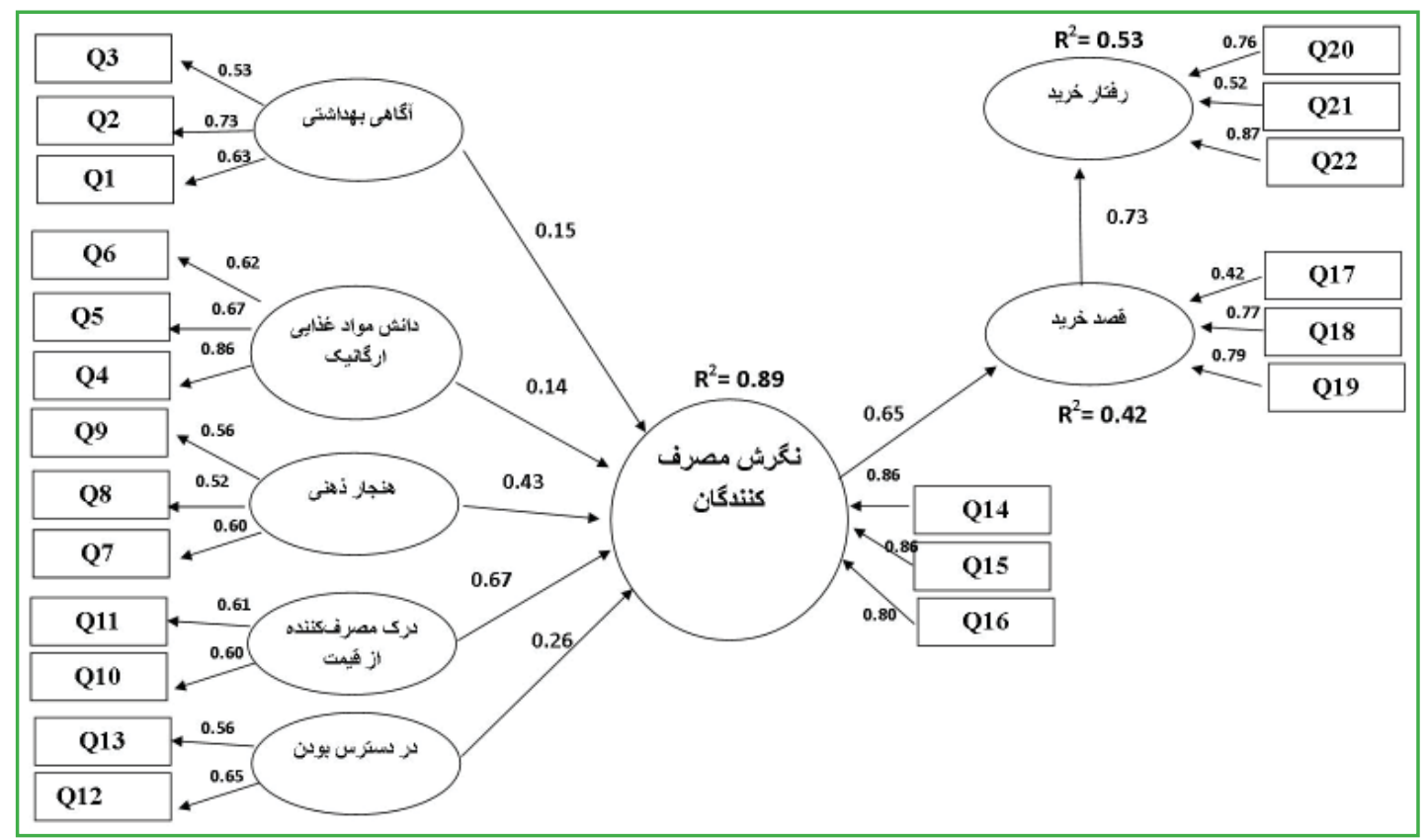

شكل ا. مدل معادلات ساختارى در حالت تخمين ضرايب استاندارد

جدول عا. شاخصهاى برازش مدل نهايى

\begin{tabular}{|c|c|c|c|}
\hline نتيجه گَيرى & مقادير مدل & بازه مورد & شاخصهاى برازش \\
\hline 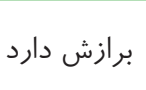 & $1 /$ & $>r$ & $\begin{array}{l}\text { كاى دو بهنجار } \\
\text { CMIN/ DF }\end{array}$ \\
\hline 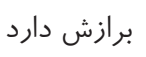 & .1945 & $\geq \cdot / 9$ & شاخص برازندگى GFI \\
\hline 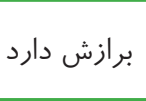 &.$/ 940$ & $\geq \cdot / \Lambda$. & شاخص تعديل يافته \\
\hline 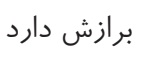 &.$/ 9 \wedge \mathrm{V}$ & $\geq \cdot / 9$ & IFI شاخص برازندگى فز آينده \\
\hline 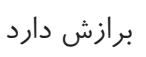 &.$/ 9 \wedge \mathrm{V}$ & $\geq \cdot / 9$ & شاخص برازندگى تطبيقى CFI \\
\hline 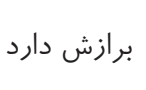 & $\cdot / \cdot r$ & $\leq . / 1$. & 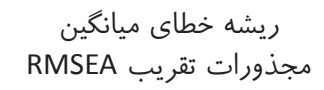 \\
\hline
\end{tabular}

برازندگى مدل بيشنهادى، بر اساس مجموعهاى از شاخصهاى

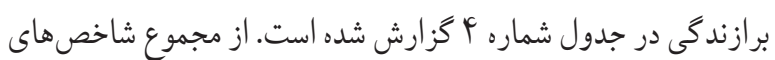

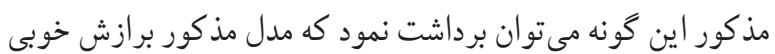
با دادههاى مطالعه داشته است.
با توجه به نتايج جدول شماره بمى توان نتيجه كرفت مدل ما

$$
\text { داراى روايى واكرا است. }
$$

با توجه به مقدار ضر ايب مسير كه در بين روابط ميان متغيرهاى تحقيق در شكل شماره ا نشان داده شده، مىتوان به اين نتيجه

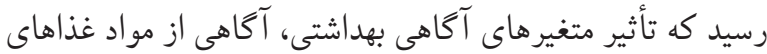

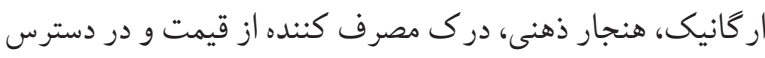

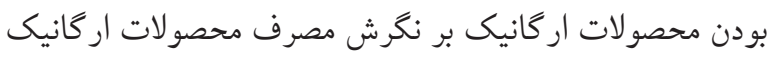

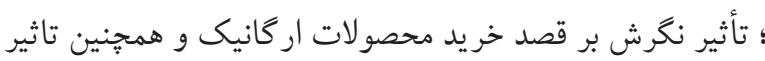

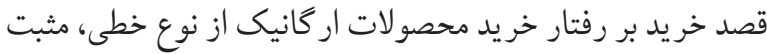

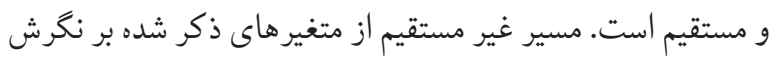

$$
\text { وجود نداشت. }
$$

ضريب تعيين R نشان مىدهد متغيرهاى مستقل روى هم رفته جقدر از رفتار متغير وابسته را ييش بينى مى كند. بر طبق

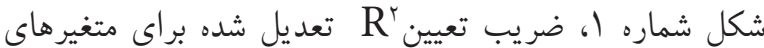

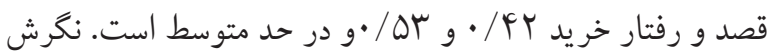

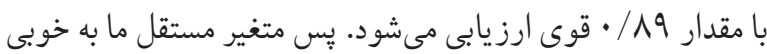
متغير هاى وابسته را سنجيدهاند. 
جدول ه. بررسى فرضيات يثوهش

\begin{tabular}{|c|c|c|c|}
\hline 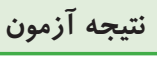 & 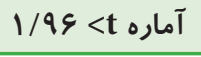 & ضريب مسير & 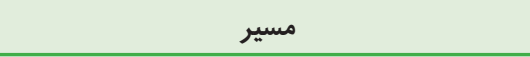 \\
\hline تأ تييد & $r / 90$ & $\cdot / 1 F$ & آكَاهى بهداشتى \\
\hline تأييد & $r / r s$ & $\cdot / 1 F$ & آكاهى از مواد غذايى اركانيك نگرش(Hr) \\
\hline تأييد & $r / r q$ &.$/ 11$ & نغرش (سץ) \\
\hline تأييد & $r / 11$ & $.19 \mathrm{~V}$ & درك مصرف كننده از قيمت \\
\hline تأييد & $r / \varsigma \hookrightarrow$ & $\cdot / r s$ & در دسترس بودن \\
\hline تأييد & $1 \cdot / 91$ & $\cdot 190$ & قصد خريد(H) \\
\hline تأييد & $14 / 19$ & $\cdot / V^{\mu}$ & ) رفتار مصرف كننده(HV) \\
\hline
\end{tabular}

سالم تر از مواد غذايى معمولى براى خود و محيط زيست مىدانند. بنابراين، آكاهى از منافع درى شده منجر به تمايل بيشتر به استفاده از غذاهاى ار كانيك مى شود (T)). در سالهاى اخير برنامهاى آموزشى رسانها سطح دانش و آكاهى افر اد را نسبت به اين محصولات بالا برده و اهميت اين محصولات براى سلامت افر اد و محيط زيست را بيان كردهاند. شايد به همين علت در اين مطالعه دو متغير آكاهى و دانش نسبت به ساير متغيرها تأثير كمترى در نكرش را نشان دادند. نتايج مطالعه Singh, Verma و Yazdanpanah نشان داد كه هنجارهاى ذهنى بر نخرش مصرف كننده نسبت به مواد غذايى ار كانيك تأثير مستقيم دارد و مشابه نتايج تحقيق حاضر مىباشد. در واقع اثرات ميان فردى ناشى از هنجارهاى اجتماعى، تاثير مثبت و معنادارى بر نگرش افر اد نسبت به مصرف محصولات ار گانيك دارد(9، ه广). انتظارات و اطلاعات ساير افراد به ويزه افراد همخروه بر ذهنيت مصرف كنند گان يك محصول تأثير گذار است. در مطالعه حاضر نيز هنجارهاى ذهنى دومين عامل تأثير گذار بر نخرش مصرف كنند گان بود. ايجاد ذهنيت مناسب براى مصرف كنند گان نسبت به مو اد غذايى ار گانيك مى تواند آنها را به سوى اين مواد سوق دهد در نتيجه استفاده از گروههاى مرجع و تبليغ آنها براى استفاده از مواد غذايى ار كانيك در سطح رسانهها مى تو اند مفيد باشد. نتايج تحقيقات SINGH, VERMA Yazdanpanah و SIth \& نشان داد كه بسيارى از مصرف كنند ₹ان قيمت را Paladino عامل مهمى در انتخاب و خريد مواد غذايى ار گانيك مىدانند. قيمت بالا از جمله نقاط ضعف در تمايل مصرف كنند
به دليل اينكه مقدار نسبت بحرانى يا همان T-value بين 99 1,99 تا 1,99- قرار ندارد موجب شده در سطح اطمينان درصد فرضيات Ho رد و فرضيات I H تأييد شود. بنا براين همه فرضيات يثزوهش تأييد شد.

بحث تحقيق حاضر، با هدف شناسايى عواملى كه ميتوانند بر نكرش مصرف كنندگان نسبت به محصولات ارگانيك تاثير بخذارند و متعاقباً مصرف كنندگان را به خريد و استفاده از اين محصولات راغب نمايند، اقدام به شناسايى عمده ترين عوامل موثر بر نكُش و قصد خريد مصرف كنندگان نسبت به محصولات ارگانيك نموده و تاثيرگذارى اين عوامل را مورد آزمون قرار داده است. نتايج حاصل از تحليل دادهها نشان داد كه متغير آكاهى بهداشتى بر نگرش مصرف كننده نسبت به مواد غذايى ار گانيك موثر است و اين مورد با مطالعات Yazdanpanah و إن Singh, Verma)

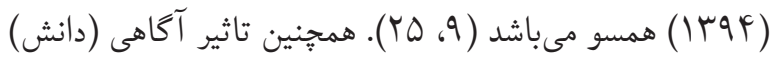
مصرف كننده از مواد غذاى ار كانيك بر نگرش مصرف كننده نسبت Singh, Verma به مواد غذايى ار گانيك تأييد شده كه با مطالعات (Y. IV) مزاياى محصولات ار گانيك موجب مىشود آنها هنگام تصميم گيرى انتخاب مواد غذايي، در مورد مزاياى بالقوه سلامت محصول فكر كنند. به عبارت ديگر، آنها علاقه مند به مسايل مرتبط با سلامت هستند و اين محصولات را مصرف مى كنند زير الين مواد غذايى را 
مصرفكنندكان ديده شده و نكرانى در مورد محيط زيست از حاشيه به يك مساله اصلى تبديل شده است. با افزايش نكرانى در مورد

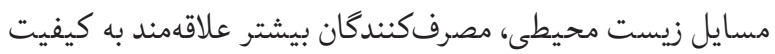

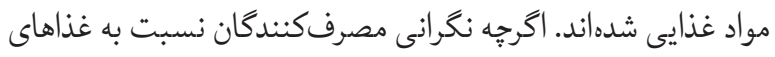
ارخانيك رو به افزايش است، اين امر به عنوان رفتارهاى خريد آنها

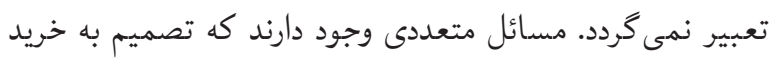

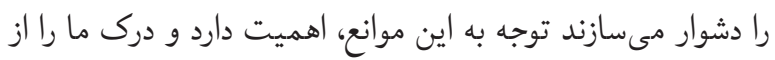
رفتار مصرفكنندگان نسبت به غذاهاى ارگانيك افزايش مى دهد. مطالعات نشان مىدهند كه قصد خريد مصرف كنندكان هميشه

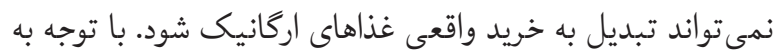
نكرانى مصرف كنندگان درمورد ايمنى بهداشت و محيط زيست، لازم است كه يك استراتزى مناسب تهيه شود. استراتثى بايد با ونان توجه به رضايت مشترى و لذت بردن مصرف كننده باشد و آكاهى و دانش مصرف كنندگان محصولات غذايى اركانيك را افزايش دهد.

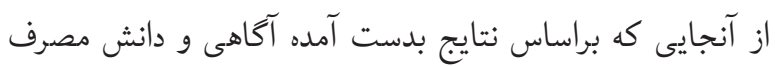

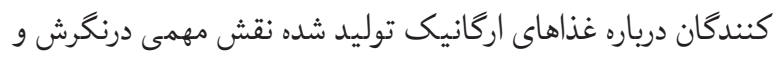

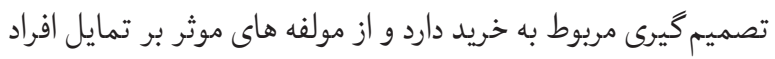

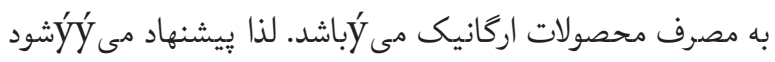
با بركزارى نمايشگاهؤهاى عرضه محصولات ارگانيك، تهيه بسته

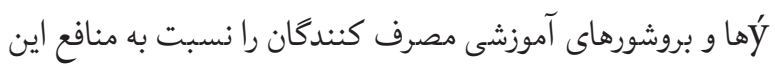
محصولات آشنا نمود و آنها را به مصرف محصولات مصروف اركانيك تشويق نمود. از طرفى نتايج نشان مىدهد دسترسى، قيمت و هنجارهاى

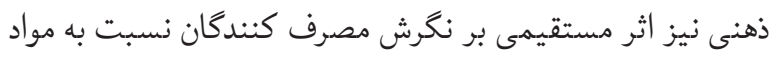

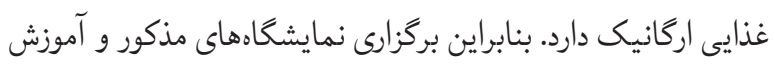
مبتنى بر مدل بر عوامل مطرح شده موثر است.

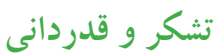
جا دارد از تمام بيمارانى كه جهت توسعه دانش بشرى با بُزوهشكران

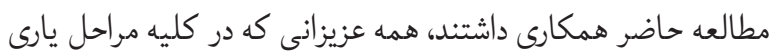
رساندند، كمال تشكر و قدردانى خويش را اعلام نماييم.

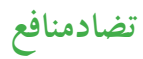
در اين مقاله هيج گونه تعارض منافع وجود ندارد.

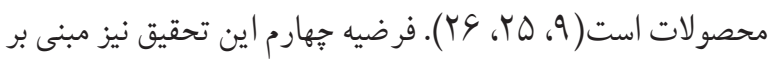

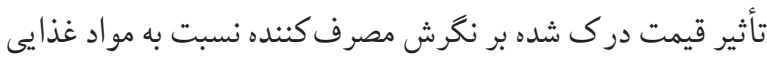
ار كانيك تاييد شد و با مطالعات مذكور همخوانى دارد. قيمت بالا از جمله ضعفهاى تكرار خريد مو اد غذايى اركانيك است. بسيارى از مصرف كنند كان بر اين باورند كه محصولات غذايى اركانيك

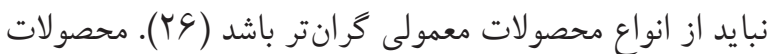

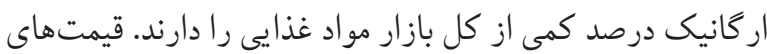

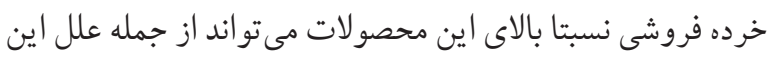

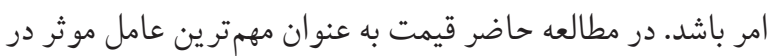
نكرش و در نتيجه قصد و رفتار خريد شناخته شد. سهولت خريد يعنى در دسترس بودن مواد غذايى، نزديكى به خانه و

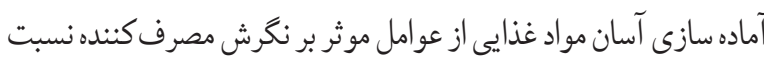
به مواد غذايى ار كانيك است. تحقيقات Hjelmar SINGH, VERMA نشان مىدهد كه سهولت خريد براى مصرف كنندگان مهم است (9، (YV).

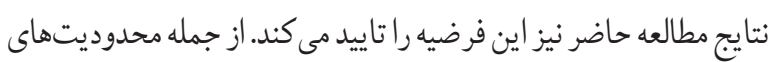
مهم در بازار محصولات ار كانيك دسترسى و سهولت خريد اين محصولات است. هنوز بازار اين محصولات شناخته شده نيست و توليدكند كان اندكى بهى اين محصولات راعرضه مى كنندو اين موضوع دسترسى مصرف كنند كان محصولات ار كانيك را محدو د به مر اكز خاص مي كند.

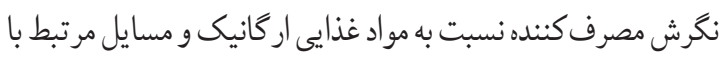

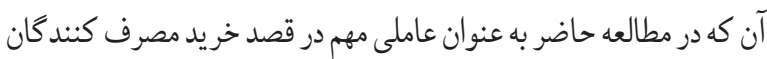
تاييد شد، در مطالعات Harrtmann و و همكاران نيز مطرح شده است (9، Y). قصد خريد يك مفهوم مناسب براى بيشبينى

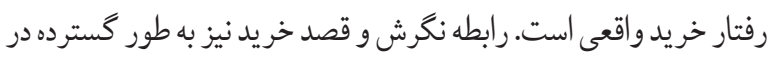

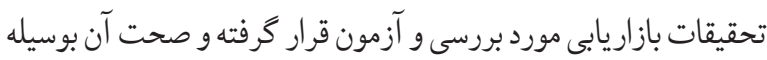

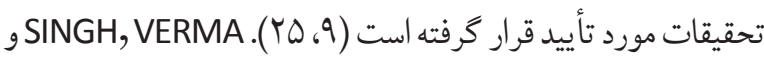
Keles. \& Bekimbetova خود به اين نتيجه رسيدند كه نكرش به محصولات سبز تاثير مثبتى بر قصد خريد اين محصولات دارد (9، 99). اين نتايج با تحقيق حاضر همسو است. نتيجاء كيرى در دههایى اخير افزايش تدريجى در آكاهىهاى زيست محيطى 


\section{References}

1. Chia-Lin Hsu a, Mu-Chen Ch., Explaining consumer attitudes and purchase intentions toward organic food: Contributions from regulatory fit and consumer characteristics. Food Quality and Preference. 2014, 35, 6-13. http://dx.doi.org/10.1016/j.foodqual.2014.01.005 [DOI:10.1016/j.foodqual.2014.01.005]

2. Razikordmahaleh L, Hatami J, Shobeiri SM, Noroozi O. Model of Education Policy for Food Safety: A Grounded Theory Study. Iranian Journal of Health Education and Health Promotion. 2018;6(4):383-92. [DOI:10.30699/ acadpub.ijhehp.6.4.383]

3. Dörthe KR, Ellen MA. Differences between Occasional Organic and Regular Organic Food Consumers in Germany. Food and Nutrition Sciences, 2014, 5, 1914-1925 Published Online October 2014 in SciRes. http://www.scirp.org/ journal/fns http://dx.doi.org/10.4236/fns.2014.519203 [DOI:10.4236/fns.2014.519203]

4. Ragvan N. Mageh R. Astudy on Consumer Purchase Intentions towards Organic Products. Paripex-Indian Journal of Research. 2013, 2(1), 111-114 [DOI:10.15373/22501991/ JAN2013/41]

5. Luttikholt LW. Principles of organic agriculture as formulated by the International Federation of Organic Agriculture Movements. NJAS-Wageningen Journal of Life Sciences. 2007;54(4):347-60. [DOI:10.1016/S15735214(07)80008-X]

6. Billen G, Garnier J, Thieu V, Silvestre M, Barles S, Chatzimpiros P. Localising the nitrogen imprint of the Paris food supply: the potential of organic farming and changes in human diet. Biogeosciences. 2012;9(1):607-16. [DOI:10.5194/bg9-607-2012]

7. Schleenbecker, R. and Hamm, U. Consumers' Perception of Organic Product Characteristics. A Review. Appetite. 2013, 71, 420-429. http://dx.doi.org/10.1016/j. appet.2013.08.020 [DOI:10.1016/j.appet.2013.08.020] [PMID]

8. Chen M.F. Consumer Attitudes and Purchase Intentions in Relation to Organic Foods in Taiwan: Moderating Effects of Food-Related Personality Traits. Food Quality and Preference, 2007, 18, 1008-1021. http://dx.doi. org/10.1016/j.foodqual.2007.04.004 [DOI:10.1016/j. foodqual.2007.04.004]

9. Singh A, Verma P. Factor's influencing Indian consumers' actual buying behavior towards organic food products. Journal of Cleaner Production; 2017.167, 473-483. DOI: $\quad 10.1016 / j . j c l e p r o .2017 .08 .106$ [DOI:10.1016/j. jclepro.2017.08.106]

10. Peattie K., Crane A. Green Marketing: Legend, Myth, Farce or Prophesy? Qualitative Market Research: An International Journal. 2005, 8(4), 357-370 [DOI:10.1108/

\section{3]}

11. Thøgersen J., Zhou Y., Huang G. How stable is the value basis for organic food consumption in China? Journal of Cleaner Production; 2016. 134 , 214-224 [DOI:10.1016/j. jclepro.2015.06.036]

12. Abdi N, Taghdisi Mh, Zamani alavijeh F, Sadeghi R. Nutrition literacy promotion, effective approach for society health promotion. Journal of Health Literacy. 2018;3(3):199-202. [DOI:10.22038/jhl.2018.35136.1015]

13. Shafie FA, Rennie D. Consumer perceptions towards organic food. Procedia-Social and Behavioral Sciences. 2012;49:360-7. [DOI:10.1016/j.sbspro.2012.07.034]

14. Brown E., Dury S., \& Holdsworth M. Motivations of consumers that use local, organic fruit and vegetable box schemes in Central England and Southern France, Appetite Journal; 2009. 53,183-188. [DOI:10.1016/j. appet.2009.06.006] [PMID]

15. Vukmirovic M. The effects of food advertising on foodrelated behaviors and perceptions in adults: A review, Food Research International; 2015. doi: 10.1016/j. foodres.2015.05.0 [DOI:10.1016/j.foodres.2015.05.011] [PMID]

16. Saleki ZS., Seyedsaleki SM., Rahimi MR. Organic food purchasing behavior in Iran. International Journal of Business \& Social Science; 2012. 3(13), 278-285

17. Gan C., Wee H. Ozanne L., Kao T. H. Consumers' purchasing behavior towards green products in New Zealand. Innovative Marketing; 2008. 4(1), 93-102

18. Makatouni A. What motivates consumers to buy organic food in the UK? Results from a qualitative study. British Food Journal; 2002. 104(3-5), 345-352 [DOI:10.1108/000 70700210425769]

19. Zundel C., Kilcher L. Issue's paper: Organic agriculture and food availability. In N. Scialabba (Ed.), Organic agriculture and food availability. Paper presented in International Conference on Organic Agriculture and Food Security. Rome, Italy: FAO. 2007, 1-25.

20. Young W., Hwang K., McDonald S., Oates C. J. Sustainable consumption: green consumer behavior when purchasing products. Sustainable Development; 2010. 18(1), 20-31. [DOI:10.1002/sd.394]

21. Shahdati A, Al-Husseini Al-Modrrasi SM. Prerequisite to Design a Health Promotion Intervention with a Social Marketing Approach to Reduce Fast Food Consumption among Students: A Formative Research with MixedMethods Approach. Iranian Journal of Health Education and Health Promotion. 2019;7(4):371-87. [DOI:10.29252/ ijhehp.7.4.371]

22. Momenpoor NI; Hassani MO; Ghasemzadeh AB. The Effec of Consumers' Perceptions on the Attitude Towards 
Organic Foods in the Yazd. Organizational Culture Management; 2018. 16(1) 195-217

23. Justin PA, Ashwin MO, Jayesh PA. Predicting green product consumption using theory of planned behavior and reasoned action. Journal of Retailing and Consumer Services; 2016. 29. 123-134. [DOI:10.1016/j. jretconser.2015.11.006]

24. Alami A, Tavakoly Sany SB, Tehrani H, Lael- Monfared E, Hosseini Z, Jafari A. The effect of educational intervention on iron and vitamin $D$ consumption based on the theory of planned behaviour in Iranian adolescent girls: a quasiexperimental study. International Journal of Health Promotion and Education. 2019;57(6):316-31. [DOI:10.10 80/14635240.2019.1632732]

25. Yazdanpanah MA, Hasheminezhad AZ. Determine Factors That Influenced Students' Intention Regarding Consumption of Organic Product: Comparison Theory of Planned Behaviour and Health Belief Model. Iranian
Journal of Agricultural Economics and Development Research. 2016, 46(4) 817-831

26. Smith, S. \& Paladino, A. Eating clean and green? Investigating consumer motivations towards the purchase of organic food, Australasian Marketing Journal (AMJ),2010; 18(2), 93-104. [DOI:10.1016/j.ausmj.2010.01.001]

27. Hjelmar, U. Consumers" purchase of organic food products, A matter of convenience and reflexive practices, Appetite,2011; 56(2), 336-344. [DOI:10.1016/j. appet.2010.12.019] [PMID]

28. Harrtmann, A., Sundqvist, S. Subjective norms, attitudes and intentions of Finnish consumers in buying organic food. British Food Journal. 2005; 107(11), 808- 822. [DOI:1 0.1108/00070700510629760]

29. Keles, I. \& Bekimbetova, T. Measuring Attitudes towards 'Green' Purchases: A Study of University Students in Kyrgyzstan. Universal Journal of Industrial and Business Management. 2013; 1(2): 46-49. 